\title{
Erratum to: Intranasal Nicotine Increases Postoperative Nausea and is Ineffective in Reducing Pain Following Laparoscopic Bariatric Surgery in Tobacco-Naïve Females: A Randomized, Double Blind Trial
}

\author{
Toby N. Weingarten ${ }^{1} \cdot$ Brian P. McGlinch ${ }^{1} \cdot$ Lavonne Liedl $^{1,2} \cdot$ Michael L. Kendrick $^{3}$. \\ Todd A. Kellogg ${ }^{3}$. Darrell R. Schroeder ${ }^{4}$. Juraj Sprung ${ }^{1}$
}

Published online: 3 July 2015

(C) Springer Science+Business Media New York 2015

Erratum to: OBES SURG (2015) 25:506-513

DOI 10.1007/s11695-014-1431-7

The title headings in Figure 1 Consort diagram study of participants-"PLACEBO NASAL SPRAY" and "NICOTINE NASAL SPRAY"-were mistakenly switched in the published diagram. Further, an additional patient in the NICOTINE NASAL SPRAY group was withdrawn because surgery was rescheduled. The diagram below shows the corrected information.

Toby N. Weingarten

Weingarten.Toby@mayo.edu

$\triangle$ Juraj Sprung

sprung.juraj@mayo.edu

Brian P. McGlinch

mcglinch.brian@mayo.edu

Lavonne Liedl

liedl.lavonne@mayo.edu

Michael L. Kendrick

kendrick.michael@mayo.edu

Todd A. Kellogg

kellogg.todd@mayo.edu
Darrell R. Schroeder schroedd@mayo.edu

Mayo Clinic Department of Anesthesiology, Mayo Clinic College of Medicine, 200 First Street SW, Rochester, MN 55905, USA

2 Mayo Clinic Anesthesia Clinical Research Unit, Mayo Clinic Department of Anesthesiology, Mayo Clinic College of Medicine, 200 First Street SW, Rochester, MN 55905, USA

3 Mayo Clinic Department of Surgery, Mayo Clinic College of Medicine, 200 First Street SW, Rochester, MN 55905, USA

4 Mayo Clinic Department of Biomedical Statistics and Informatics, Mayo Clinic College of Medicine, 200 First Street SW, Rochester, MN 559051, USA 
Assessed for eligibility $(n=328)$

August 2010-March 2014

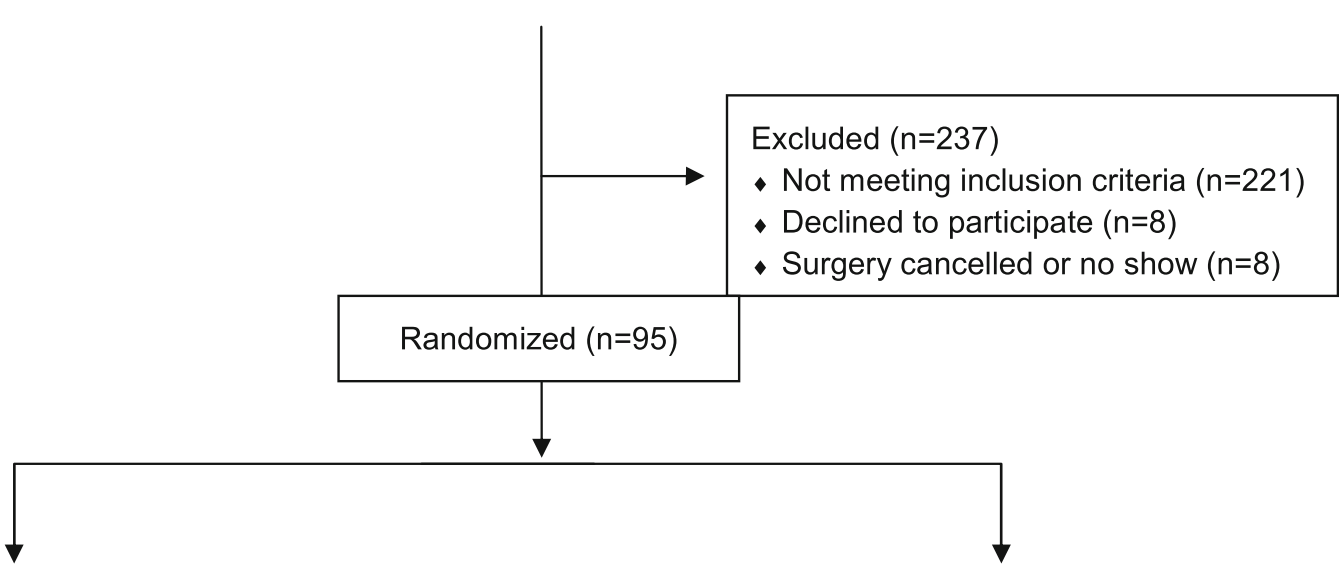

\section{NICOTINE NASAL SPRAY}

Allocated to intervention $(n=47)$

- Received allocated intervention $\mathrm{N}=42$

- Withdrew consent prior to surgery $(n=3)$

- $\quad$ Surgery cancelled $(n=1)$

- $\quad$ Surgery rescheduled $(n=1)$

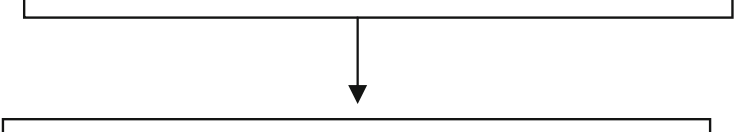

Analysed $(n=42)$
PLACEBO NASAL SPRAY

Allocated to intervention $(n=48)$

- Received allocated intervention $\mathrm{N}=47$

- $\quad$ Surgery rescheduled $(n=1)$

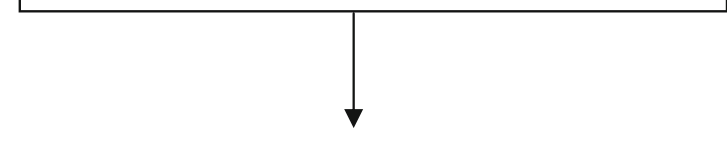

Analysed $(n=47)$ 